\title{
A transformerless inverter with virtual dc bus concept for grid-connected PV power systems
}

\author{
T. PARANDHAMAIAH ${ }^{1}$, M. HARINARAYANA ${ }^{2}$, Dr. B. DURGA PRASAD ${ }^{3}$ \\ PG Student [ES], Dept. of ME, JNTUA College of Engineering, Ananthapuramu, Andhra Pradesh, India ${ }^{1,2}$ \\ Professor, Dept. of ME, JNTUA College of Engineering, Ananthapuramu, Andhra Pradesh, India ${ }^{3}$
}

\begin{abstract}
The traditional grid-connected PV inverter includes either a line frequency or a high frequency transformer between the inverter and grid. The transformer provides galvanic isolation between the grid and the PV panels. In order to increase the efficiency, to reduce the size and cost, the effective solution is to remove the isolation transformer. It leads to appearance of common mode (CM) ground leakage current due to parasitic capacitance between the PV panels and the ground. The common mode current reduces the efficiency of power conversion stage, affects the quality of grid current, deteriorate the electric magnetic compatibility and give rise to the safety threats. In order to eliminate the common mode leakage current in transformer less PV system, the concept of virtual DC bus is proposed. By connecting the grid neutral line directly to the negative pole of the DC bus, the stray capacitance between the PV panels and the ground is bypassed. The CM ground leakage current can be suppressed completely. Virtual DC bus is created to provide the negative voltage level for the negative AC grid current generation. The virtual DC bus is realized with the switched capacitor technology that uses less number of elements. Therefore, the power electronic cost can be reduced. This topology can be modulated with the unipolar SPWM to reduce the output current ripple. A smaller filter inductor can be used to reduce the size and magnetic losses. The simulation result of the proposed topology using MATLAB/SIMULINK is analysed in detail, with the results verified by a prototype.
\end{abstract}

Keywords: Photovoltaic (PV) system, Common mode (CM), Unipolar sinusoidal pulse width modulation (SPWM), Transformerless inverter, Virtual dc bus.

\section{I.INTRODUCTION}

Renewable energy sources become a more and electronics systems. The efficiency and reliability of both more important contribution to the total energy production single-phase and three phase PV inverter systems can be in the world. Today the energy production from solar improved using transformerless topologies, but new energy compared to the other renewable energy sources is problems related to leakage current and safety need to be very low, but the PV systems are one of the fastest dealt with. The size and cost of the inverter need to be growing in the world. The price of PV system reduced. components, especially the PV modules are decreasing and the market for PV is expanding rapidly. Solar power will be dominant because of its availability and reliability. Photovoltaic inverters become more and more widespread within both private and commercial circles. These gridconnected inverters convert the available direct current supplied by the PV panels and feed it into the utility grid. According to the latest report on installed PV power, during 2012, there has been a total of $69.3 \mathrm{GW}$ of installed PV systems in power in the world. At the end of 2012, the total installed PV capacity will reach $80.0 \mathrm{GW}$ of which around $90 \%$ is grid connected. There are two main inverter topologies used in the case of grid-connected PV systems, namely, with and without galvanic isolation. Galvanic isolation can be on the dc side in the form of a highfrequency dc-dc transformer or on the grid side in the form of a big bulky ac transformer. Both of these solutions offer the safety and advantage of galvanic isolation, but the efficiency of the whole system is decreased due to power losses in these extra components. In case the transformer is omitted, the efficiency of the whole PV system can be increased with an extra $1 \%-2 \%$. The efficiency of commercial PV panels is around 15-20\%. Therefore, it is very important that the power produced by these panels is not wasted, by using inefficient power

The efficiency of commercial PV panels is around $15-20 \%$. Therefore, it is very important that the power produced by these panels is not wasted, by using inefficient power electronics systems. The efficiency and reliability of both single-phase and three phase PV inverter systems can be improved using transformerless topologies, but new problems related to leakage current and safety need to be dealt with. The size and cost of the inverter need to be reduced. The main goal of this project is to analyze and model transformerless PV inverter systems with respect to the leakage current phenomenon that can damage the solar panels and pose safety problems. New topologies and control strategies that will minimize the leakage current, reduce the size, cost and exhibit a high efficiency is proposed, and verified.

\section{REVIEW OF EXISTING INVERTER TOPOLOGIES}

\section{A. Common Mode Current}

If the transformer is omitted, the common mode (CM) ground leakage current may appear on the parasitic capacitor between the PV panels and the ground. The existence of the CM current may reduce the power conversion efficiency, increase the grid current distortion, deteriorate the electric magnetic compatibility, and more 
importantly, give rise to the safety threats. The CM current bridge inverter and neutral point clamped (NPC) half path in the grid-connected transformerless PV inverter bridge inverter, then the required DC bus voltage should system is illustrated in Fig.1. It is formed by the power be doubled compared with the full bridge topologies. switches, filters, ground impedance ZG and the parasitic Beside the classic circuits above, there are other topologies capacitance $\mathrm{CPV}$ between the PV panels and the ground. According to, the CM current path is equivalent to an LC resonant circuit in series with the $\mathrm{CM}$ voltage, as shown in Fig.2. The CM voltage vCM is defined by

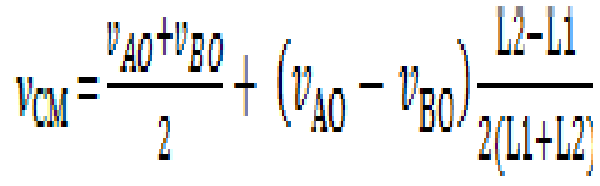

Where vAO is the voltage difference between point $\mathrm{A}$ and $\mathrm{O}, \mathrm{vBO}$ is the voltage difference between point $\mathrm{B}$ and $\mathrm{O}$, and $\mathrm{L} 1$ and $\mathrm{L} 2$ are the output filter inductors. If the switching action of the inverter generates high frequency $\mathrm{CM}$ voltage, the $\mathrm{CM}$ current $\mathrm{iCM}$ may be exited on the LC circuit. From this point of view, the topology and modulation strategy adopted for the transformerless PV power system should guarantee that $\mathrm{vCM}$ is constant or only varies at low frequency, such as $50 \mathrm{~Hz} / 60 \mathrm{~Hz}$ line frequency.

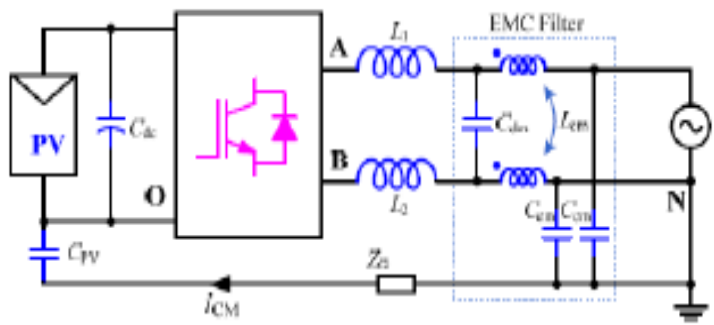

Fig 1. CM current path for transformerless PV Inverter

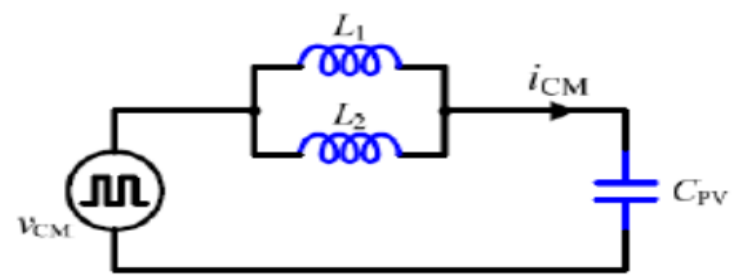

Fig 2. Equivalent circuit for current path

\section{B. State-of-the-art Topologies}

One of the ways to realize this goal is to use full bridge inverter with the bipolar sinusoidal pulse width modulation (SPWM). Though the unipolar SPWM has better performance when compared to bipolar SPWM, it cannot be used directly for the full bridge inverter because it generates switching frequency $\mathrm{CM}$ voltage. For this reason, some of the topologies based on the full bridge inverter with unipolar SPWM such as the H5 inverter, the HERIC inverter, H6 inverter with AC bypass and H6 inverter with DC bypass have been developed. Such inverter topologies require two filter inductors which may lead to a rise in the size and cost. The DC and AC sides cannot be perfectly disconnected by the power switches because of the switch parasitic capacitance, so the common mode current may still exist. If half bridge inverter topologies are used such as conventional half proposed in recent literatures. The Karschny inverter and the paralleled-buck inverter are derived from the buckboost and buck circuits respectively. These solutions have high reliability, but are not capable of supplying the reactive power to the grid. The inverter proposed in employs a capacitor voltage divider to keep the CM voltage constant, but is regarded to be of higher conduction losses.

\section{PROPOSED TOPOLOGY AND MODULATION}

Based on the negative voltage generation concept, an inverter topology is derived to show the clear advantages of the proposed methodology, which is shown in Fig.3. It consists of five power switches S1 S5 and only one single filter inductor $L f$. The PV panels and capacitor $C 1$ form the real DC bus while the virtual DC bus is provided by $C 2$. With the switched capacitor technology, $C 2$ is charged by the real DC bus through $\mathrm{S} 1$ and $\mathrm{S} 3$ to maintain a constant voltage. This topology can be modulated with the unipolar SPWM and double frequency SPWM. The detailed analysis is introduced as follows.

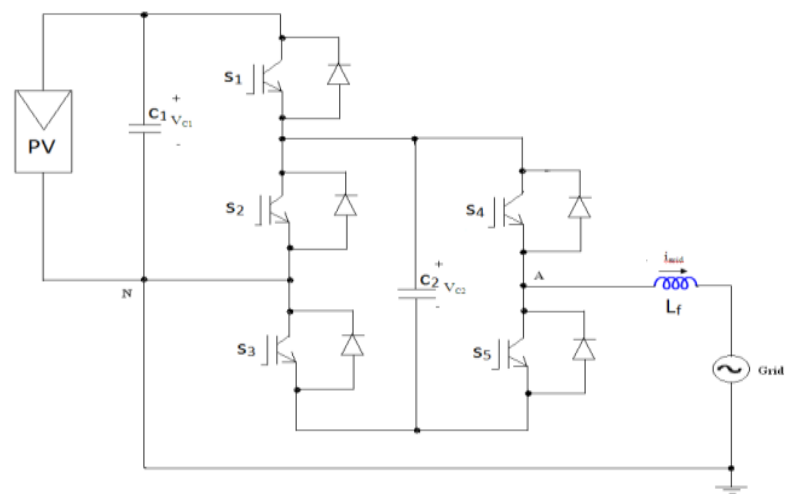

Fig 3. Proposed Topology

\section{A. Unipolar SPWM}

The waveform for the unipolar SPWM of the proposed inverter is displayed in Fig.4. The gate drive signals for the power switches are generated according to the relative value of the modulation wave $u \mathrm{~g}$ and the carrier wave $u \mathrm{c}$. During the positive half grid cycle, $u \mathrm{~g}>$ 0 . S1 and S3 are turned on and S2 is turned off, while S4 and S5 commutate complementally with the carrier frequency. The capacitors $C 1$ and $C 2$ are in parallel and the circuit rotates between state 1 and state 2 as shown in Fig.5. During the negative half cycle, $u \mathrm{~g}<0$. S5 is turned on and S4 is turned off. S1 and S3 commutate with the carrier frequency synchronously and S2 commutates in complement to them. The circuit rotates between state 3 and state 2. At state 3, S1 and S3 are turned off while S2 is turned on. The negative voltage is generated by the virtual DC bus $C 2$ and the inverter output is at negative voltage level. At state 2, S1 and S3 are turned on while S2 is turned off. The inverter output voltage $v \mathrm{AN}$ equals zero, meanwhile $C 2$ is charged by the DC bus through $\mathrm{S} 1$ and S3. 


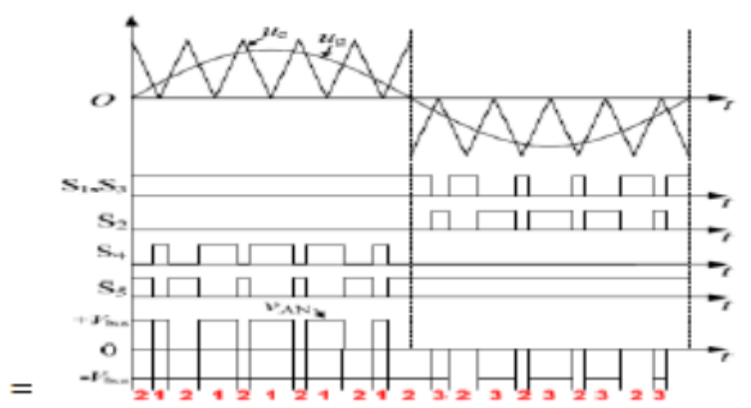

Fig 4 Unipolar SPWM for proposed topology
TABLE I. SUMMARY OF OPERATION OF SWITCHES

\begin{tabular}{|l|l|l|l|l|l|}
\hline \multirow{2}{*}{ STATE } & \multicolumn{4}{|l|}{ SWITCHES } \\
\cline { 2 - 6 } & $\mathrm{S}_{1}$ & $\mathrm{~S}_{2}$ & $\mathrm{~S}_{3}$ & $\mathrm{~S}_{4}$ & $\mathrm{~S}_{5}$ \\
\hline 1 & ON & OFF & ON & ON & OFF \\
\hline 2 & ON & OFF & ON & OFF & ON \\
\hline 3 & OFF & ON & OFF & OFF & ON \\
\hline 4 & OFF & ON & OFF & ON & OFF \\
\hline
\end{tabular}

The summary of operation state of the switches for proposed topology is shown in Table 1.

\section{SIM POWERSYSTEMS}

SimPowerSystems is a modern design tool that allows scientists and engineers to rapidly and easily build models that simulate power systems. SimPowerSystems uses the Simulink environment, allowing you to build a model using simple click and drag procedures. Not only can you draw the circuit topology rapidly, but your analysis of the circuit can include its interactions with mechanical, thermal, control, and other disciplines. This is possible because all the electrical parts of the simulation interact with the extensive Simulink modelling library. Since Simulink uses MATLAB ${ }^{\circledR}$ as its computational engine, designers can also use MATLAB toolboxes and Simulink block sets. SimPowerSystems and Sim Mechanics share a special SimPowerSystems Libraries. You can rapidly put SimPowerSystems to work. The libraries contain models of typical power equipment such as transformers, lines, machines, and power electronics. These models are proven ones coming from textbooks, and their validity is based on the experience of the Power Systems Testing and Simulation Laboratory of Hydro-Québec, a large North American utility located in Canada, and also on the experience of Ecolab de Technologies Superiors and University Laval.

The capabilities of SimPowerSystems for modelling a typical electrical system are illustrated in demonstration files. And for users who want to refresh their knowledge of power system theory, there are also self-learning case studies. The SimPowerSystems main library, power lib, organizes its blocks into libraries according to their behavior. The power lib library window displays the block library icons and names. Double-click a library icon to open the library and access the blocks. The main SimPower Systems power lib library window also contains the Powerful block that opens a graphical user interface for the steady-state analysis of electrical circuits.

\section{A) Simulation snapshot}

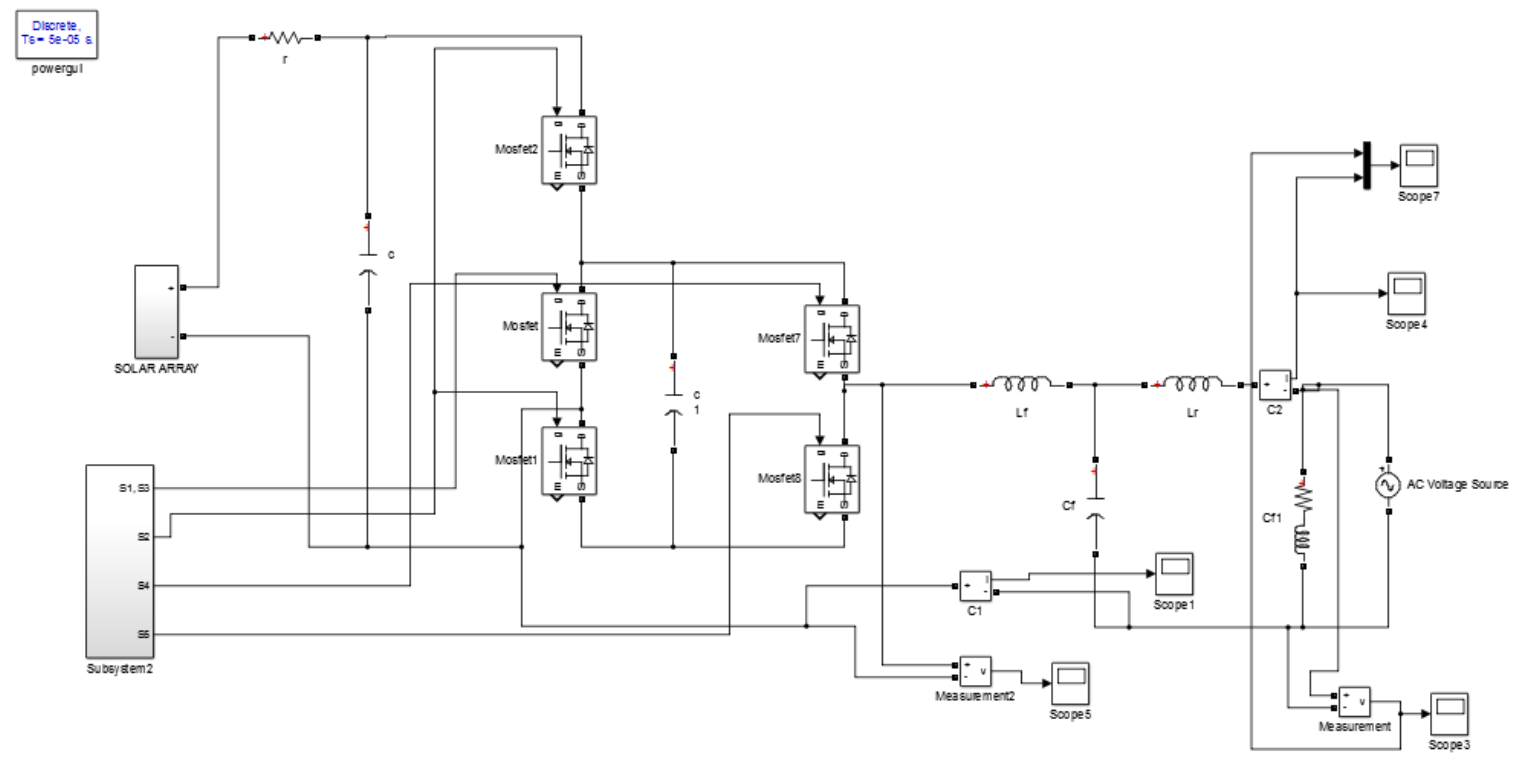


INTERNATIONAL JOURNAL OF INNOVATIVE RESEARCH IN ELECTRICAL, ELECTRONICS, INSTRUMENTATION AND CONTROL ENGINEERING Vol. 3, Issue 1, January 2015

(i) Subsystem

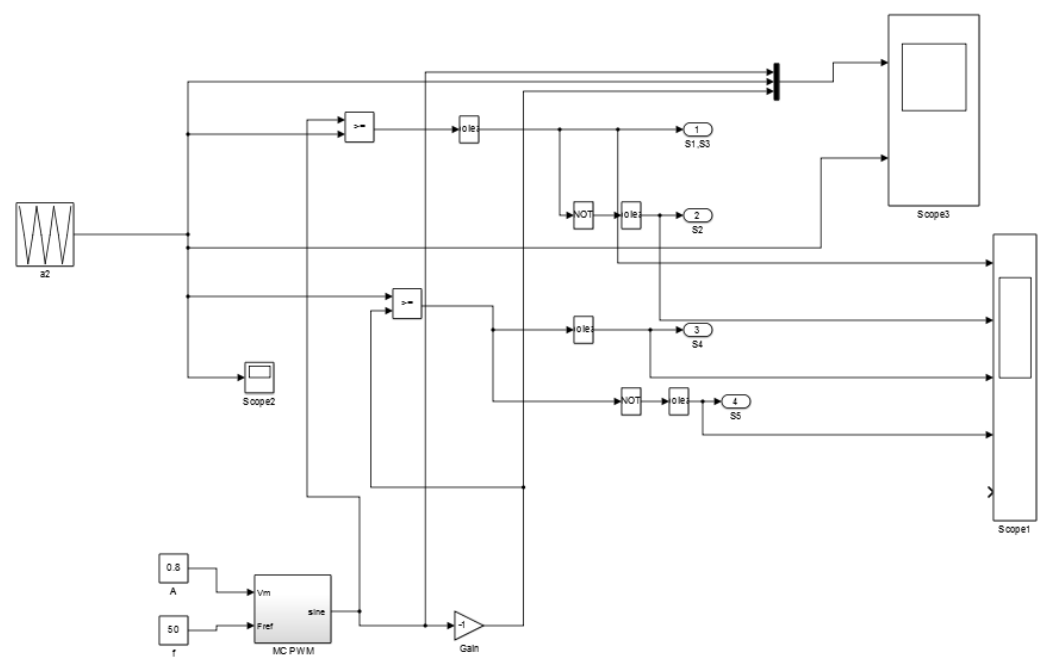

\section{B) Output}

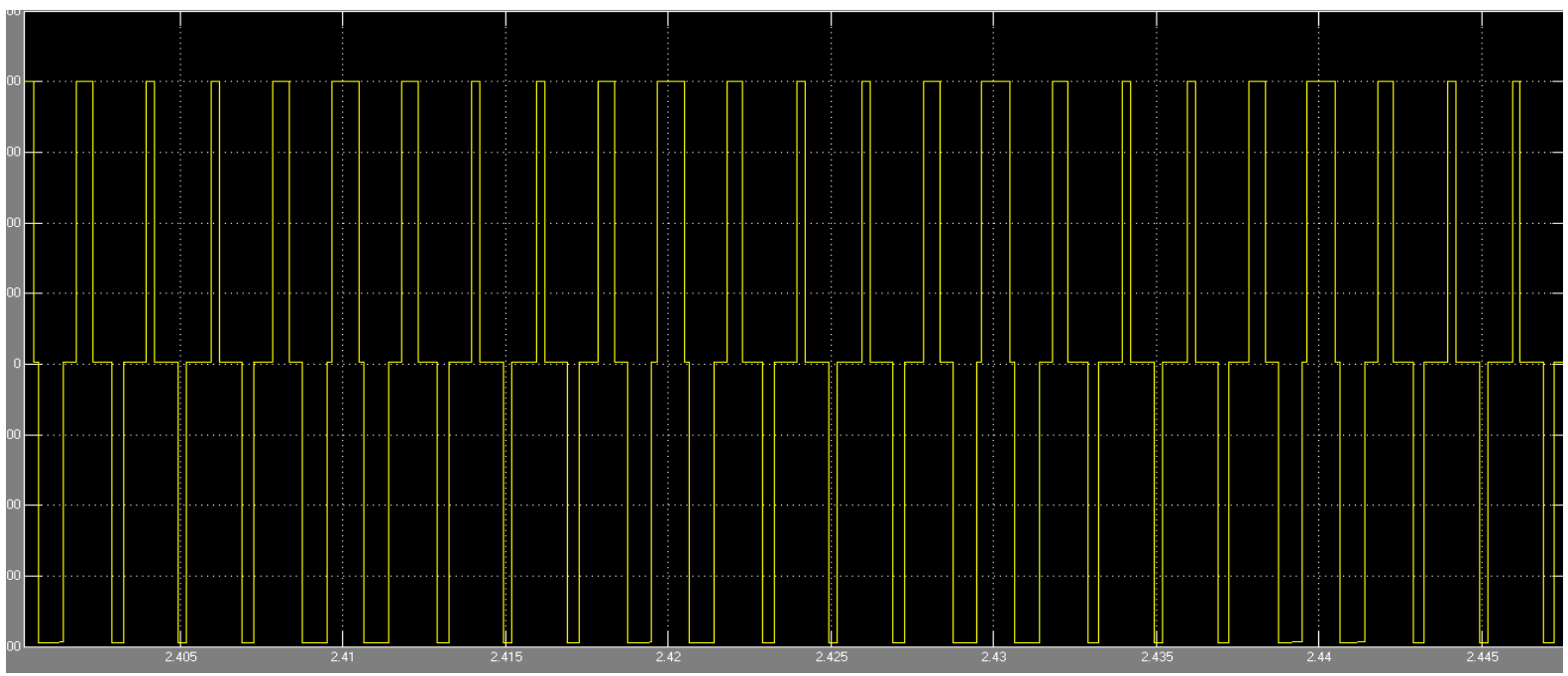

(i) Grid voltage

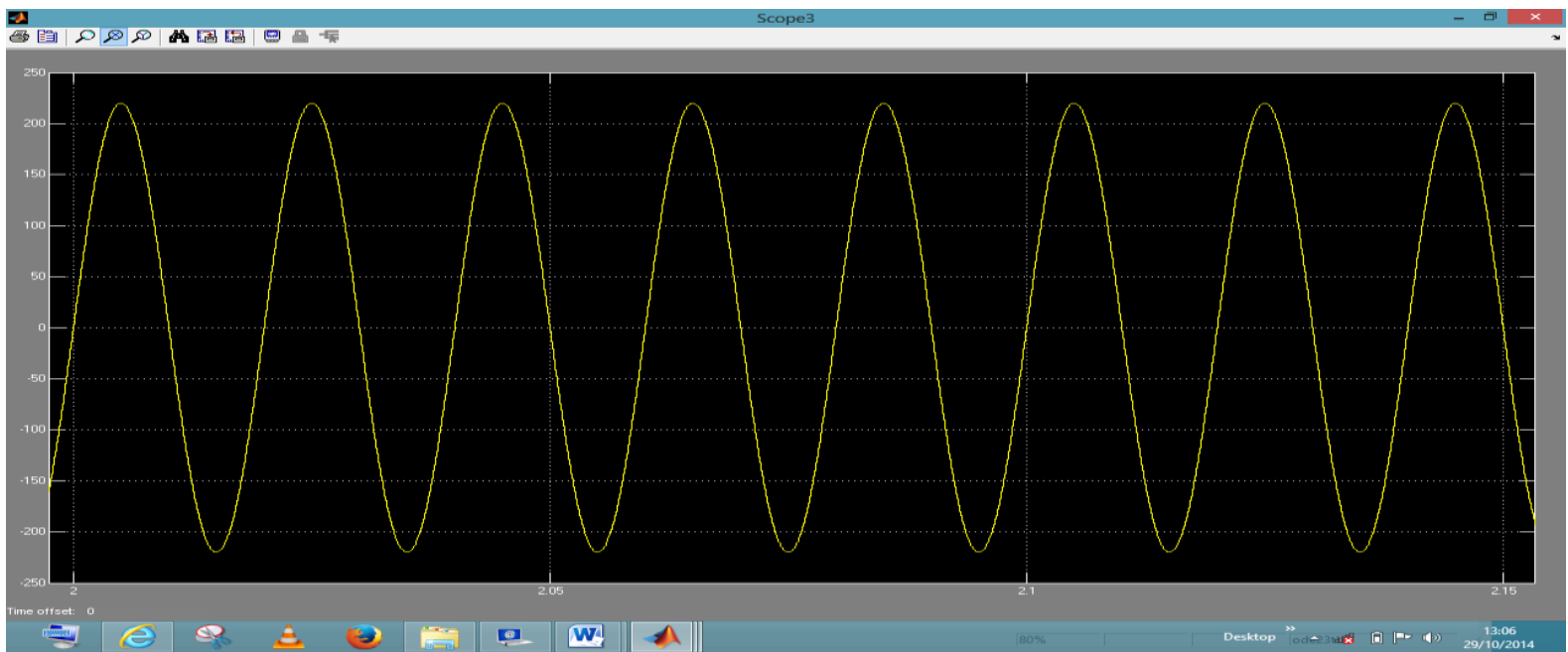


INTERNATIONAL JOURNAL OF INNOVATIVE RESEARCH IN ELECTRICAL, ELECTRONICS, INSTRUMENTATION AND CONTROL ENGINEERING Vol. 3, Issue 1, January 2015

\section{(ii) Grid current}

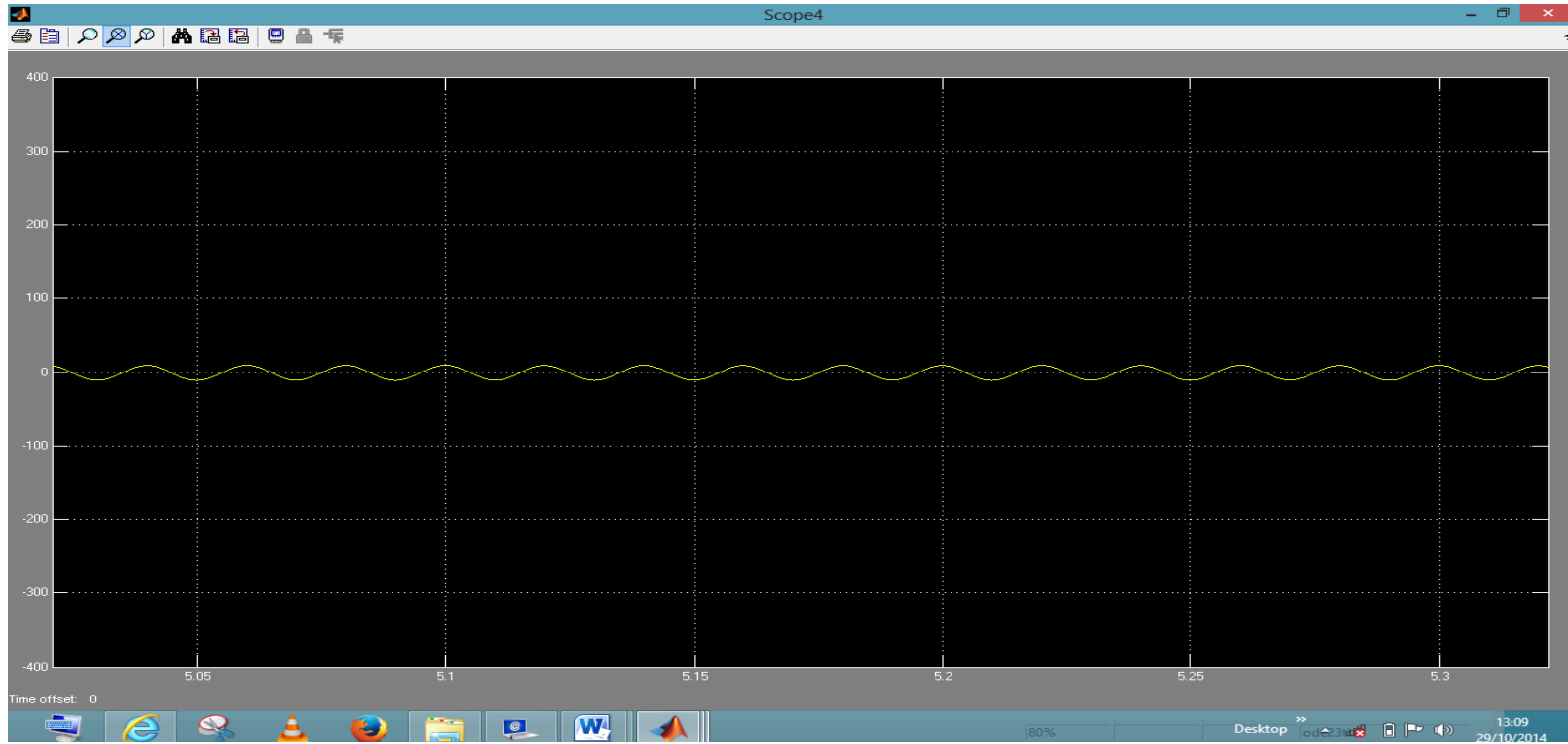

\section{C) DRIVER CIRCUIT}

EROM MICRO CONTROLLER

D1

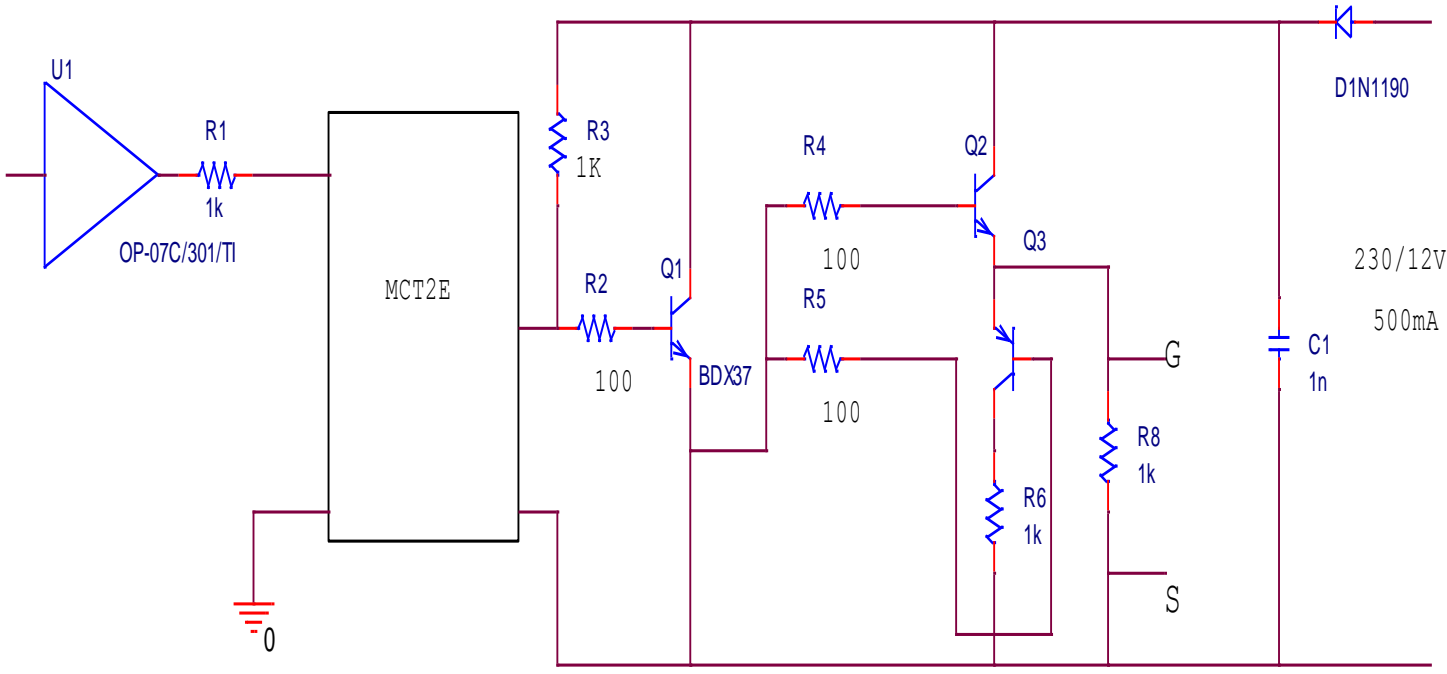

Fig 5.Driver circuit

The driver circuit is supplied using a step down transformer $230 \mathrm{~V} / 12 \mathrm{~V}$ AC. In this project the driver circuit is mainly used to amplify the pulse output coming from the microcontroller circuit.

The output from pin 1 and 2 of PIC16F877A is passed to the buffer IC CD4050 .The buffer IC acts as a NOT gate the output from the buffer IC is passed to the two optocoupler respectively. The optocoupler is used to isolate the voltages between the main circuit and microcontroller circuit. This signal is passed to the transistors CK100 and 2N2222 which is connected in a Darlington pair model. The driver circuit has two legs. First leg is connected to switch-1 Sm and the second leg is connected to switch-2 Sa. Thus the 5V pulse from the microcontroller circuit is amplified to $12 \mathrm{~V}$ and sent to MOSFET switch. 


\section{D) Picture of Prototype}

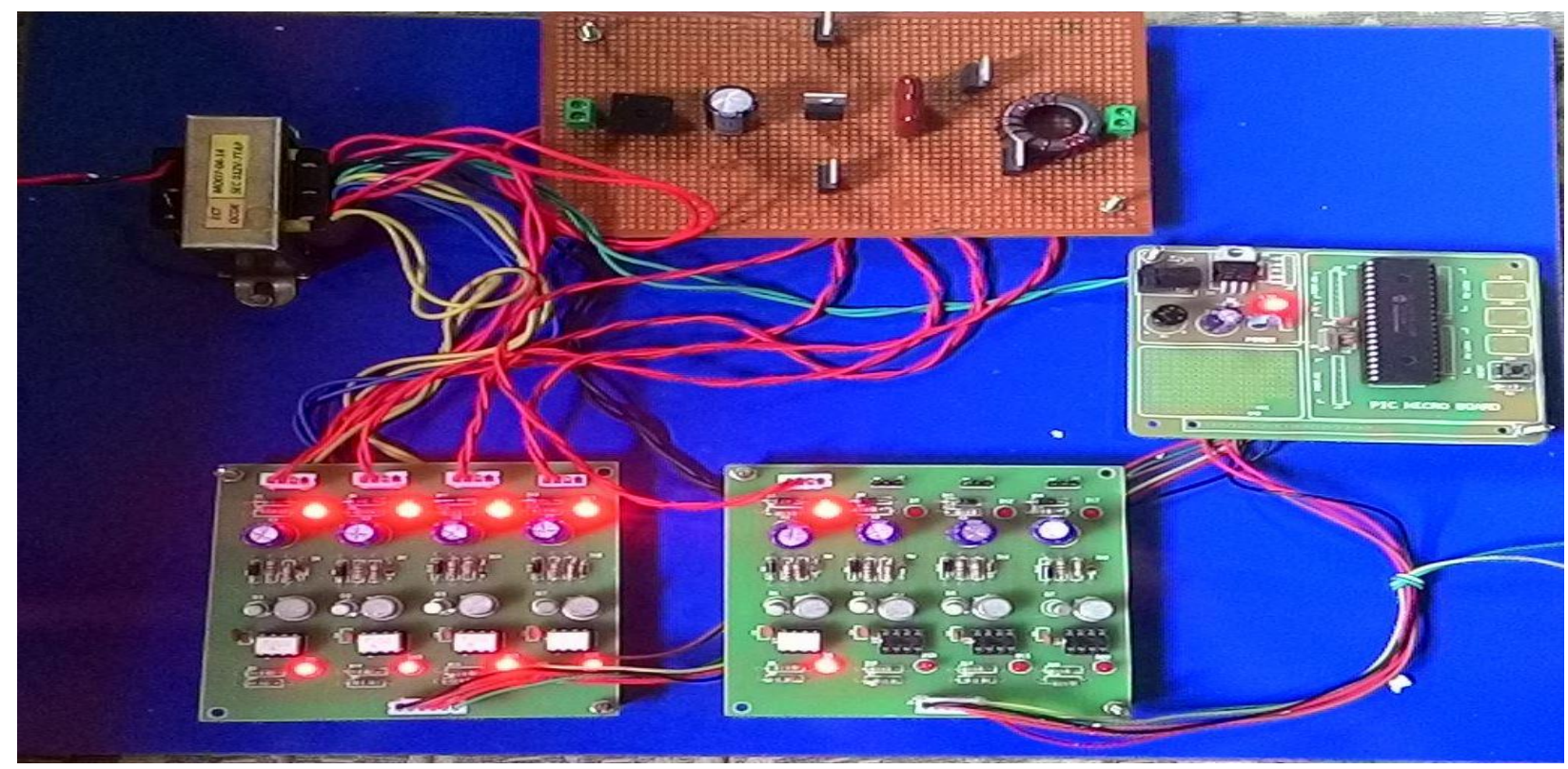

(i) Prototype level output

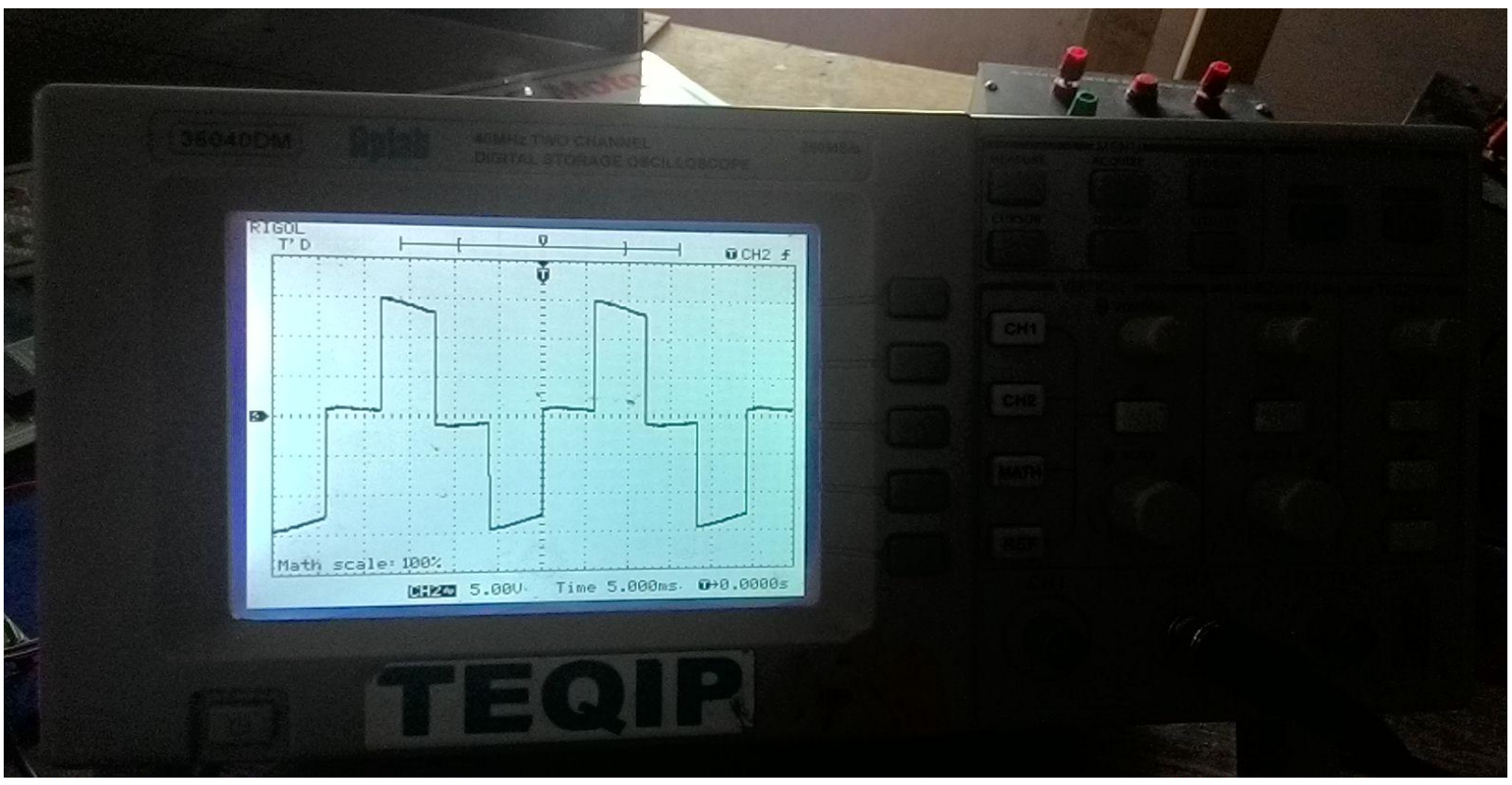

\section{V.CONCLUSION}

The concept of the virtual DC bus is proposed to solve the CM current problem for the transformerless grid-connected PV inverter. By connecting the negative pole of the DC bus directly to the grid neutral line, the voltage on the stray PV capacitor is clamped to zero. This eliminates the CM current completely. Meanwhile, a virtual DC bus is created to provide the negative voltage level. The required DC voltage is only half of the half bridge solution, while the performance in eliminating the CM current is better than the full bridge based inverters. Based on this idea, a novel inverter topology is proposed with the virtual DC bus concept by adopting the switched capacitor technology. It consists of only five power switches and a single filter inductor. The proposed topology is especially suitable for the small power single phase applications, where the output current is relatively small so that the extra current stress caused by the switched capacitor does not cause serious reliability problem for the power devices and capacitors. With excellent performance in eliminating the CM current, the virtual DC bus concept provides a promising solution for the transformerless grid-connected PV inverters. The software tool used in this project is MATLAB 2012b. 


\section{REFERENCES}

[1] T. Kerekes, R. Teodorescu, P. Rodríguez, Vázquez, G. E. Aldabas, "A New High-Efficiency Single-Phase Transformerless PV Inverter Topology," Industrial Electronics, IEEE Transactions on , vol.58, no.1, pp.184-191, Jan. 2011

[2] O. Lopez, F.D. Freijedo, A.G. Yepes, P. Fernandez-Comesaa, J. Malvar, R. Teodorescu, J.Doval-Gandoy, "Eliminating Ground Current in a Transformerless Photovoltaic Application," Energy Conversion, IEEE Transactions on , vol.25, no.1, pp.140-147, March 2010.

[3] E. Gubía, P. Sanchis, A. Ursúa, J. Lopez, and L. Marroyo, "Ground currents in single-phase transformerless photovoltaic systems," Prog.Photovolt., Res. Appl., vol. 15, pp. 629-650, 2007.

[4] S.V. Araujo, P. Zacharias, B. Sahan, "Novel grid-connected nonisolated converters for photovoltaic systems with grounded generator," Power Electronics Specialists Conference, 2008.PESC 2008.IEEE, vol., no., pp.58-65, 15-19 June 2008.

[5] B. Yang, W. Li, Y. Gu, W. Cui, X. He, "Improved Transformerless Inverter With Common-Mode Leakage Current Elimination for a Photovoltaic Grid-Connected Power System," Power Electronics, IEEE Transactions on , vol.27, no.2, pp.752-762, Feb. 2012.I. S. Jacobs and C. P. Bean, "Fine particles, thin films and exchange anisotropy," in Magnetism, vol. III, G. T. Rado and H. Suhl, Eds. New York: Academic, pp. 271-350, 1963.

[6] German Patent Wechselrichter: DE 19642522 C1, April 1998.

[7] S.V. Araujo, P. Zacharias, R. Mallwitz, , "Highly Efficient SinglePhase Transformerless Inverters for Grid-Connected Photovoltaic Systems," Industrial Electronics, IEEE Transactions on , vol.57, no.9, pp.3118-3128, Sept. 2010.

[8] D. Barater, G. Franceschini, E. Lorenzani, "Unipolar PWM for transformerless grid-connected converters in photovoltaic plants," Clean Electrical Power, 2009 International Conference on, vol., no., pp.387-392, 9-11 June 2009.

[9] TarakSalmi, MounirBouzguenda, Adel Gastli, Ahmed Masmoudi "MATLAB/Simulink Based Modelling of Solar Photovoltaic Cell" International journal of Renewable Energy Research, R. Nicole, "Title of paper with only first word capitalized," J. Name Stand. Abbrev in press, Vol.2, No.2, 2012. 